\title{
FUNGSI KEPOLISIAN DALAM MENANGGULANGI KEJAHATAN PREMANISME DI PELABUHAN BAJO'E KABUPATEN BONE
}

\author{
The Function of the Police in Addressing Crimes of Thuggery in the Bajo'e Port of Bone Regenc \\ Rahmat Hidayat ${ }^{1}$, Abdul Salam Siku ${ }^{2}$, Abdul Haris Hamid ${ }^{2}$ \\ ${ }^{1}$ Mahasiswa Program Studi Ilmu Hukum Program Pascasarjana Universitas Bosowa \\ ${ }^{2}$ Program Studi Ilmu Hukum Universitas Bosowa \\ Email: 44rahmathidayat@gmail.com
}

Diterima: 08 Agustus 2019/Disetujui: 09 Desember 2019

\begin{abstract}
ABSTRAK
Penelitian ini bertujuan untuk mengetahui faktor-faktor yang menyebabkan terjadinya kejahatan di pelabuhan Bajo'e Kabupaten Bone, dan upaya kepolisian untuk mengatasi kejahatan Premanisme di pelabuhan Bajo'e Kabupaten Bone. Penelitian ini dilaksanakan di Polsek Pelabuhan. Metode penelitian yang digunakan adalah hukum empiris yaitu merupakan penelitian hukum sosiologis, yaitu mengkaji ketentuan hukum yang berlaku serta apa yang terjadi dalam kenyataanya di masyarakat, dan menggunakan berbagai data primer dan sekunder adapun data primer yang digunakan yaitu melalui wawancara langsung kepada narasumber yang berkaitan dengan tulisan ini dan membagikan angket kepada responden, adapun data sekunder dengan mengumpulkan data dari berbagi literatur yang ada, berupa buku, artikel-artikel yang diperoleh dari penelusuran internet, termasuk aturan perundang-undangan yang terkait dengan permasalahan dalam penelitian ini. Hasil penelitian menunjukkan bahwa: (1) faktor-faktor penyebab terjadinya kejahatan premanisme yaitu faktor lingkungan, factor ekonomi, dan faktor rendahnya pendidikan. (2) Upaya kepolisian untuk mengatasi kejahatan premanisme di pelabuhan Bajo'e kabupaten bone yaitu, dalam upaya pre-emtif pihak kepolisian melakukannya dengan cara menanamkan nilainilai/norma-norma yang baik kepada masyarakat melalui penyuluhan hukum dan keagamaan. Dalam upaya preventif pihak kepolisian melakukan patroli dan pengawasan secara rutin dan berkelanjutan. Sedangkan dalam upaya represif pihak kepolisian melakukan penyelidikan, penangkapan dan pembinaan psikologis dan penyadaran disertai latihan-latihan keterampilan kerja dalam masa hukuman agar punya modal untuk mencari pekerjaan.
\end{abstract}

Kata Kunci: Kejahatan, Premanisme, Kepolisian, Bajoe, Bone

\begin{abstract}
This study aims to determine the factors that led to the occurrence of crime in the Bajo'e district of Bone port, and the police efforts to overcome the crime of thuggery in the port of Bajo'e Bone. This research was conducted at the Port Police Station. The research method used is empirical law which is a sociological legal research, which examines the applicable legal provisions and what happens in reality in the community, and uses a variety of primary and secondary data while the primary data used is through direct interviews with sources related to writing this and distributing questionnaires to respondents, as for secondary data by collecting data from sharing existing literature, in the form of books, articles obtained from internet searches, including legislation related to the problems in this study. The results of the authors obtained from this study, namely (1) factors that cause the occurrence of thuggery namely environmental factors, economic factors, and educational factors. (2) Police efforts to overcome the crime of thuggery in Bajo'e regency bone port, namely: In the pre-eminent effort the police did it by instilling good values / norms with the community through legal and religious counseling. In preventive efforts the police conduct regular and ongoing patrols and supervision. Whereas in repressive efforts the police conduct investigations, arrests and psychological coaching and awareness accompanied by work skills training in the period of punishment so that they have the capital to find work.
\end{abstract}

Keywords: Crime, Thuggery, Police, Bajoe, Bone

\section{PENDAHULUAN}

Setiap orang berhak untuk hidup serta berhak untuk mempertahankan hidupnya dan kehidupannya. Hal ini sesuai dengan amanat dari Pasal 28 A Undang-Undang Dasar 1945. Dewasa ini Pemerintah telah berupaya dalam memaksimalkan kesejahteraan hidup masyarakat. Pemerintah, dalam hal bidang ekonomi telah memberikan perhatian dan prioritasnya yang bertujuan untuk meningkatkan kualitas hidup masyarakat dengan harapan bahwa kondisi sosial ekonomi masyarakat kita, dapat menjadi membaik. Namun yang terjadi saat ini, 
kesejahteraan masyarakat untuk hidup seringkali terganggu saat melakukan aktivitas-aktivitas dalam meningkatkan kualitas hidupnya di dalam bidang ekonomi dikarenakan oleh faktor krimi-nalitas yang merupakan bagian dari tindak kejahatan yang se-makin meningkat dan sangat memperngaruhi kehidupan dalam bermasyarakat (Eddy, 2016; Frank, 2017).

Kepolisian Republik Indonesia mengemban 2 (dua) tugas pokok antara lain Tugas Preventif dan Tugas Represif. Tugas Preventif berupa patroli-patroli yang dilakukan secara terarah dan teratur, menjaga ketertiban dan memelihara ketertiban umum, termasuk usaha pencegahan kejahatan (Rodo, 2018). Sedangkan Tugas Represif dilakukan dengan menghimpun bukti-bukti sehubungan de-ngan pengusutan perkara dan bahkan berusaha untuk menemukan kembali barang-barang hasil curian, melakukan penahanan untuk kemudian diserahkan kepada kejaksaan yang akan meneruskannya ke Pengadilan (Basran, 2015).

Perilaku premanisme di kota-kota yang memiliki perkembangan arus globalisasi yang sangat pesat dapat dikatakan sangat tinggi. Meningkatnya angka kriminalitas di kota - kota besar dengan arus globalisasi yang tinggi menyebabkan perilaku premanisme akan semakin marak. Dengan bermunculnya kelompok-kelompok preman, sangat jelas telah menebar ancaman ketakutan dan keresahan di kalangan masyarakat. Karena dalam aksinya mereka tidak segan-segan berlaku sadis sampai dengan tega membantai korban tanpa rasa kemanusiaan (DPN, 2008;Basran, Bambang, 2016).

Premanisme adalah perilaku yang meresahkan serta dapat mengganggu keamanan dan ketertiban masyarakat. Aksi-aksi premanisme dewasa ini semakin meningkat setelah ada beberapa bagian dari anggota masyarakat yang tidak mampu merasakan kesejahteraan ekonomi seperti anggota masyarakat lainnya. Sebagian besar mereka yang melakukan premanisme tidak memiliki pekerjaan dan tidak memiliki keterampilan yang memadahi, sehingga mencari jalan pintas dengan cara memalak, memeras, merampok, dan mengintimidasi. Sebagai contoh dalam bab ini, aksi premanisme yang sering dilakukan adalah adanya pungutan liar terhadap pedagang kaki lima dan penjualpenjual yang apabila ditolak untuk memberikan maka akan berpengaruh terhadap kesalamatan jiwa dan dagangannya (Topo dan Eva, 2003;Suyanto, 2018).

Selain perbuatan-perbuatan seperti memalak, memeras, merampok, mengintimidasi serta kekerasan yang dilakukan. Aksi Premanisme juga sering melakukan penganiayaan yang menyebabkan luka dan berakibat akan kematian seseorang. Selain itu preman dan premanisme menjadi masalah ketika kehidupan yang normal tidak berjalan, ketika mereka terorganisir, dan juga ketika mereka menjadi bagian dari gerakan atau aktivitas politik, gerakan kedaerahan ataupun gerakan berbasis agama, dan kegiatan bisnis. Ketika itulah toleransi terhadap preman dan premanisme harus tidak boleh ada, dan hukum harus bisa diterapkan dengan tegas terhadap mereka dan pihakpihak yang berada dibelakang mereka atau pengguna mereka.

Kepolisian dalam hal ini berkaitan dengan fungsinya sebagai pengayom masyarakat mempunyai peran yang sangat besar dalam upaya penanggulangan terhadap premanisme. Pihak kepolisian yang begitu dekat dengan masyarakat diharapkan mampu mengambil tindakan yang tepat dalam menyikapi fenomena-fenomena preman di masyarakat (Momo, 1972;Ninik, 1987).

Berdasarkan hal tersebut, dilakukan penelitian secara mendalam terhadap permasalahan yang berkaitan dengan berbagai macam tindak pidana yang dilakukan oleh para pelaku preman di sekitar masyarakat. Untuk itu, dilakukan penelitian tentang Fungsi Kepolisian dalam Menanggulangi Kejahatan Premanisme Di Pelabuhan Bajo'e".

Tujuan penelitian ini adalah untuk mengkaji, (a) faktor-faktor yang menyebabkan adanya tindakan premanisme di pelabuhan Bajo'e Kabupaten Bone dan upaya kepolisian dalam menanggulangi premanisme di pelabuhan Bajo'e Kabupaten Bone.

\section{METODE}

Penelitian ini dilaksanakan di Polsek Pelabuhan Bajo'e Kabupaten Bone. Metode penelitian yang digunakan adalah hukum empiris yaitu jenis penelitian hukum sosiologis dan dapat disebut pula denga penelitian lapangan, yaitu mengkaji ketentuan hukum yang berlaku serta apa yang terjadi dalam kenyataanya di masyarakat. adapun jenis dan sumber data yang digunakan yaitu data primer melalui wawancara langsung kepada narasumber yang berkaitan dengan tulisan ini, dan data sekunder dengan mengumpulkan data dari berbagi literatur yang ada, berupa buku, artikel-artikel yang diperoleh dari berbagai penelusuran internet, termasuk aturan per-undang-undangan yang terkait dengan permasalahan dalam penelitian ini.

\section{HASIL DAN PEMBAHASAN}

\section{Data Kasus Kejahatan Premanisme di Pelabuhan Bajo'e Kabupaten Bone}

Tahun 2016 terdapat 5 kasus yang dilaporkan, 4 (80\%) diantaranya dapat diselesaikan sedangkan 1 (20\%) kasus yang tidak selesai, dan pada tahun 2017 tercatat ada 2 (100 $\%)$ laporan kasus premanisme yang masuk di Polsek Pelabuhan, $2(100 \%)$ yang selesai, sedangkan pada tahun 2018, tercatat ada 2 laporan kejahatan premanisme yang masuk di Polsek Pelabuhan, $1(50 \%)$ diantaranya dapat terselesaikan dengan dan 1 (50\%) kasus yang tidak selesai selesai.

Tabel 1.

Jumlah Kejahatan Premanisme di Polsek Pelabuhan Tahun 2016-2018

\begin{tabular}{ccccc}
\hline Tahun & $\begin{array}{c}\text { Laporan } \\
\text { Premanisme }\end{array}$ & Selesai & $\begin{array}{c}\text { Tidak } \\
\text { Selesai }\end{array}$ & $\begin{array}{c}\text { Selesai dan Tidak } \\
\text { Selesai }(\%)\end{array}$ \\
\hline 2016 & 5 & 4 & 1 & $80 \%: 20 \%$ \\
2017 & 2 & 2 & - & $100 \%$ \\
2018 & 2 & 1 & 1 & $50 \%: 50 \%$ \\
\hline Jumlah & 9 & 7 & 2 & $71,42 \%: 29,68 \%$ \\
\hline
\end{tabular}

Sumber : Data Primer yang diolah

Dapat diketahui bahwa kejahatan Premanisme di wilayah Polsek Pelabuhan, pada tahun 2016-2018 sebanyak 9 kasus dan sebanyak 7 kasus diproses hingga selesai dan 2 kasus yang tidak selesai dari semua kasus yang terjadi, hampir seluruhnya dapat diselesaikan oleh pihak kepolisian. 
Tabel 2.

Jumlah Temuan Jenis-Jenis Kejahatan yang dilakukan oleh Preman di Polsek Pelabuhan Tahun 2016-2018

\begin{tabular}{clccc}
\hline No. & \multicolumn{1}{c}{$\begin{array}{c}\text { Jenis Kejahatan } \\
\text { Preman }\end{array}$} & 2016 & $\begin{array}{r}\text { Tahun } \\
2017\end{array}$ & 2018 \\
\hline 1 & Penganiayaan & 1 & - & - \\
2 & Pengroyokan & 1 & & - \\
3 & $\begin{array}{l}\text { Pencurian dengan } \\
\text { ancaman kekerasan }\end{array}$ & 1 & 1 & 1 \\
4 & Pemerasaan & 2 & 1 & 1 \\
\hline & $\quad$ Jumlah & 5 & 2 & 2 \\
\hline
\end{tabular}

Sumber : Data Primer yang diolah

Berdasarkan Tabel 2. dapat dilihat jenis-jenis tindak kejahatan yang dilakukan oleh preman di Pelabuhan Bajo'e mulai dari tahun 2016 sampai dengan tahun 2018 ada 4 jenis kejahatan, dengan incian sebagai berikut: Tahun 2016 terdapat 5 kasus kejahatan yang dilakukan preman di antaranya penganiayaan sebanyak 1 kasus, pengeroyokan sebanyak 1 kasus, pencurian dengan ancaman kekerasan sebanyak 1 kasus, pemerasaan sebanyak 2 kasus. Tahun 2017 terdapat 2 kasus yang dilakukan oleh preman di antaranya pencurian dengan kekerasan sebanyak 1 kasus dan pemerasan sebanyak 1 kasus. Tahun 2018 terdapat 1 kasus kejahatan yang dilakukan oleh preman yaitu pemerasan sebanyak 1 kasus dan pencurian dengan kekerasan sebanyak 1 kasus. Pembagikan beberapa angket kepada orang-orang di Pelabuhan Bajo'e Kabupaten Bone kepada 50 orang di Pelabuhan Bajo'e Kabupaten secara rinci dapat dilihat pada Tabel 3 di bawah ini :

Tabel 3

Jumlah Responden

\begin{tabular}{|c|c|c|c|c|c|}
\hline \multirow[t]{2}{*}{ No. } & \multirow[t]{2}{*}{ Pertanyaan } & \multicolumn{2}{|c|}{$\begin{array}{l}\text { Tang- } \\
\text { gapan }\end{array}$} & \multicolumn{2}{|c|}{ Persentase } \\
\hline & & $\mathrm{Ya}$ & Tidak & $\mathrm{Ya}$ & Tidak \\
\hline 1 & $\begin{array}{l}\text { Apakah anda pernah } \\
\text { menjadi korban } \\
\text { premanisme }\end{array}$ & 43 & 7 & $86 \%$ & $14 \%$ \\
\hline 2 & $\begin{array}{l}\text { Semenjak adanya preman } \\
\text { di pelabuhan Bajo'e, anda } \\
\text { semakin waspada } \\
\text { menjaga harta benda yang } \\
\text { anda miliki }\end{array}$ & 50 & - & $100 \%$ & $0 \%$ \\
\hline 3 & $\begin{array}{l}\text { Apakah Kepolisian Sering } \\
\text { memberikan penyuluhan } \\
\text { untuk mengurangi tingkat } \\
\text { kejahatan premanisme di } \\
\text { pelabuhan Bajo'e }\end{array}$ & 31 & 19 & $62 \%$ & $38 \%$ \\
\hline 4 & $\begin{array}{l}\text { Apakah Anggota } \\
\text { Kepolisian Sering } \\
\text { Melakukan Patroli untuk } \\
\text { mempersempit ruang } \\
\text { gerak preman }\end{array}$ & 42 & 8 & $84 \%$ & $16 \%$ \\
\hline 5 & $\begin{array}{l}\text { Apakah anda melaporkan } \\
\text { kasus ini ketika anda } \\
\text { menjadi korban } \\
\text { premanisme di pelabuha } \\
\text { Bajo'e }\end{array}$ & 15 & 35 & $30 \%$ & $70 \%$ \\
\hline & Jumlah & 181 & 69 & $72,4 \%$ & $27,6 \%$ \\
\hline
\end{tabular}

Sumber: Data primer
Berdasarkan Tabel 3 dapat diketahui bahwa yang pernah menjadi korban premanisme menanggapi Ya sebanyak $43(86 \%)$ responden dan Tidak sebanyak 7 (14\%) responden, dimana 18 responden menjadi korban kejahatan premanisme di kapal dan 25 di angkutan umum, pertanyaan ke 2 semenjak adanya preman di pelabuhan Bajo'e semakin waspada menjaga harta benda yang dimiliki yang menanggapi Ya sebanyak $50(100 \%)$ responden, pertanyaan ke 3 Pihak Kepolisian sering memberikan penyuluhan hukum yang menanggapi Ya sebanyak 31 (62\%) responden dan Tidak sebanyak 19 responden (38\%), pertanyaan ke 4 Pihak Kepolisian sering melakukan Patroli yang menanggapi Ya sebanyak $42(84 \%)$ responden dan Tidak sebanyak 8 responden $(16 \%)$, pertanyaan ke 5 yang melaporkan kasus ketika menjadi korban premanisme di Pelabuhan Bajo'e yang menanggapi Ya sebanyak 15 (30\%) responden dan Tidak sebanyak 35 (70 \%) responden. Adapun Total Jumlah keseluruhan Tanggapan Ya sebanyak 181 (72, $4 \%$ ) dan Tidak Sebanyak 69 (27, 6 \%).

\section{Faktor-faktor Penyebab Terjadinya Kejahatan Premanisme di Pelabuhan Bajo'e Kabupaten Bone.}

Disamping adanya faktor-faktor tersebut, dari hasil penelitian diperoleh beberapa faktor yang menyebabkan preman tindakan premanisme antara lain :

\section{a. Faktor lingkungan}

Faktor lingkungan ini merupakan faktor banyaknya preman melakukan kejahatan di beberapa wilayah, mereka yang berinteraksi langsung dengan warga untuk melakukan tindak kejahatan sebagian besar di lakukan dengan cara berkelompok atau geng.

\section{b. Faktor ekonomi}

Preman biasanya melakukan tindak kejahatan dilatarbelakangi karena masalah ekonomi, dimana mereka menggantungkan hidupnya terhadap hasil dari kejahatan seperti mencuri, memalak. Sehinggah dianggap sebagai pekerjaan tetap yang bisa mendatangkan keuntungan di dalam memenuhi kebutuhan hidupnya sehari-hari.

\section{c. Faktor pendidikan}

Pada umumnya preman melakukan tindak kejahatan memiliki tingkat pendidikan yang sangat rendah. Alasannya karena sejak kecil mereka mengenyam pendidikan rata-rata hanya sampai tingkat Sekolah Dasar. Hal seperti ini diakibatkan karena cara mendidik orang tua yang salah yang tidak memiliki rencana untuk anak-anaknya melanjutkan pendidikan ke jenjang yang lebih tinggi, sehingga ada yang buta huruf, kurang fasih berbahasa Indonesia. Kemudian orang tua mereka jarang tinggal dirumah bersama keluarga untuk mendidik dan membina anak-anaknya (Hamdan, 1995). Oleh karena bekal pendidikan di dapat sangat kurang sebagai modal untuk bersaing mencari lapangan kerja, sehingga tidak ada jalan yang harus ditempuh selain melakukan tindak kejahatan seperti mencuri, memalak.

\section{d. Faktor minuman keras (miras)}

Minuman keras sangat besar dampaknya bagi preman yang melakukan tindak kejahatan, sebab dampak dari meminum minuman keras (miras) membuat seseorang menjadi tidak terkontrol dan berani melakukan perbuatan nekad termasuk melakukan aksi kejahatan seperti, merampok, melakukan kekerasan, memalak, serta tidak segan-segan membuat onar di tempat umum, sehingga membuat masyarakat dirugikan. 
Tabel 4.

Faktor yang melatarbelakangi sehingga Preman melakukan Kejahatan

\begin{tabular}{|c|c|c|c|c|c|c|}
\hline \multirow{2}{*}{ No } & \multirow{2}{*}{ Pertanyaan } & \multicolumn{4}{|c|}{ Faktor )* } & \multirow{2}{*}{ Jumlah } \\
\hline & & 1 & 2 & 3 & 4 & \\
\hline 1 & $\begin{array}{l}\text { Apa yang } \\
\text { melatarbela } \\
\text { kangi } \\
\text { sehingga } \\
\text { anda } \\
\text { melakukan } \\
\text { kejahatan } \\
\text { premanisme }\end{array}$ & 1 & 5 & 2 & 1 & 9 \\
\hline \multicolumn{2}{|c|}{ Persentase } & $\begin{array}{c}11,1 \\
\%\end{array}$ & $\begin{array}{c}55,6 \\
\%\end{array}$ & $\begin{array}{c}22,2 \\
\%\end{array}$ & $\begin{array}{c}11,1 \\
\%\end{array}$ & $100 \%$ \\
\hline & $\begin{array}{r}\text { angan : } 1=\text { lin } \\
\text { Pend }\end{array}$ & $\begin{array}{l}\text { Ingan, } \\
\text { kan; }\end{array}$ & $\begin{array}{l}=\mathrm{eko} \\
\text { minu }\end{array}$ & $\begin{array}{l}\text { mi; } \\
\text { an keras }\end{array}$ & & $3=$ \\
\hline
\end{tabular}

Berdasarkan Tabel 4 dapat kita lihat kalau maraknya preman melakukan tindak kejahatan yang terjadi di Pelabuhan Bajo'e, dari 9 kasus 5 (55,6 \%) kasus dipengaruhi oleh faktor ekonomi, $1(11,1 \%)$ kasus dipengaruhi oleh faktor lingkungan, $2(22,2 \%)$ kasus dipengaruhi oleh faktor pendidikan, dan $1(11,1 \%)$ kasus dipengaruhi oleh faktor minuman keras (miras).

\section{Upaya Kepolisian Untuk Menanggulangi Premanisme di Pelabuhan Bajo'e Kabupaten Bone}

\section{a. Upaya Pre-Emtif}

Merupakan upaya awal yang dilakukan oleh pihak kepolisian untuk mencegah terjadinya tindak pidana. Usahausaha yang dilakukan dalam penanggulangan secara PreEmtif adalah menanamkan nila-nilai/ norma-norma yang baik kepada masyarakat. Dalam penanggulangan preman secara pre-emtif pihak Polsek Pelabuhan telah mengadakan penyuluhan hukum kepada masyarakat. Penyuluhan hukum tersebut dilaksanakan dengan bekerja sama dengan Pemerintah Kabupaten Bone dan instansi terkait.

\section{b. Upaya Preventif}

Upaya ini merupakan tindak lanjut dari upaya PreEmtif yang masih dalam tataran pencegahan sebelum terjadinya kejahatan. Dalam upaya preventif yang ditekankan adalah menghilangkan kesempatan untuk dilakukannya kejahatan. Upaya ini berupa patroli dan pengawasan secara rutin dan berkelanjutan. Kegiatan ini dilakukan oleh pihak Polsek Pelabuhan di tempat-tempat yang rawan dilakukannya tindakan premanisme. berikut ini merupakan upaya-upaya preventif dalam penanggulangan tindak premanisme yaitu :

a) Melakukan operasi dan pengawasan di tempat-tempat keramaian

b) Mengadakan Patroli dan Pengawasan secara Rutin dan Berkelanjutan.

c) Melakukan penyelidikan atau pengintaian

\section{c. Upaya Represif}

Dalam upaya secara represif pihak Polsek Pelabuhan melaksanakan operasi khusus yang disebut dengan sandi "Operasi Street Crime" yang pelaksanaanya telah diatur secara terstruktur oleh POLRI. Polsek Pelabuhan melakukan penindakan upaya hukum terhadap aksi-aksi pre-manisme, baik premanisme individu, premanisme kelompok maupun terhadap premanisme aparat. Penindakan hukum yang dimaksud adalah dengan melakukan razia secara ter-struktur dan penangkapan terhadap pelaku premanisme yang terjaring dalam razia.

Razia serupa juga secara serentak dilakukan di beberapa daerah. Razia premanisme yang digelar jajaran polisi dilakukan untuk mengurangi dan menekan tindak kriminal, dan juga membuat rasa aman dan nyaman kepada masyarakat. Razia terhadap preman-preman dilakukan di setiap titik dimana menurut laporan masyarakat di daerah tersebut banyak dijumpai preman-preman yang meresahkan masyarakat. Tempat-tempat tersebut antara lain di terminal-terminal, pasar-pasar, dan tempat umum lainnya. Pihak Polsek Pelabuhan beserta jajarannya menangkap semua preman yang berada di tempat-tempat tersebut dan membawanya untuk kemudian diperiksa apakah mereka terkait tindak kejahatan atau tidak, jika mereka terkait maka mereka akan ditahan untuk dilakukan tindakan lebih lanjut dan jika tidak mereka akan dibawa ke panti rehabilitasi untuk mendapatkan binaan.

\section{KESIMPULAN}

Berdsasarkan hasil penelitian dapat disimpulkan bahwa faktor-faktor yang menyebabkan terjadinya Kejahatan Premanisme di Pelabuhan Bajo'e Kabupaten Bone, yaitu: faktor ekonomi sebanyak 5 kasus $(55,6 \%)$, faktor rendahnya pendidikan sebanyak 2 kasus $(22,2 \%)$, faktor lingkungan sebanyak 1 kasus $(11,1 \%)$, dan minuman keras sebanyak 1 kasus $(11,1 \%)$. Adapun faktor yang paling dominan yaitu faktor ekonomi sebanyak 5 kasus (55, $6 \%$ ); dan Fungsi Kepolisian dalam menanggulangi kejahatan Pre-manisme di pelabuhan Bajo'e Kabupaten Bone dapat dilihat dari upaya yang dilakukan Polisi, baik secara pre-emtif, preventif, maupun represif. Dalam upaya pre-emtif pihak kepolisian melakukannya dengan cara menanamkan nilai-nilai/normanorma yang baik kepada masyarakat melalui penyuluhan hukum dan keagamaan. Dalam upaya preventif pihak kepolisian melakukan patroli dan pengawasan secara rutin dan berkelanjutan. Sedangkan dalam upaya represif pihak kepolisian melakukan penyelidikan, penangkapan dan pembinaan psikologis dan penyadaran disertai latihanlatihan keterampilan kerja dalam masa hukuman agar punya modal untuk mencari pekerjaan.

\section{DAFTAR PUSTAKA}

Bambang Waluyo. (2016). Penegakan Hukum Di Indonesia. Penerbit. Jakarta. Sinar Grafika

Basran Basri. (2015). Tinjauan Kriminologis Terhadap Kejahatan Penganiayaan Yang Dilakukan Preman di Kabupaten Pangkep (Studi Kasus di Polres Pangkep Tahun 2012-2014). Fakultas Hukum. Universitas Hasanuddin. Makassar.

[DPN] Departemen Pendidikan Nasional. (2008). Kamus Besar Bahasa Indonesia Pusat Bahasa. Penerbit. PT. Gramedia Pustaka Utama. Jakarta

Eddy O.S. Hiariej. (2016). Prinsip-Prinsip Hukum Pidana (Edisi Revisi). Penerbit. Cahaya Atma. Yogyakarta.

Frank E. Hagan. (2017). Pengantar Kriminologi. Teori. Metode. dan Perilaku Kriminal. Penerbit. Prenada Media. Jakarta.

Hamdan. M. (1995). Penanggulangan Masalah Preman Ditinjau dari Sudut Politik Kriminil. Jurnal Hukum dan Pembangunan. 1995. 
http://id.wikipedia.org/wiki/premanismeMoeljatno. (2009). Asas-asas Hukum Pidana. Penerbit. Bina Aksara. Jakarta.

Momo Kelana. (1972). Hukum Kepolisian. Perkembangan di Indonesia Suatu Studi Histories Komparatif. Penerbit. PTIK. Jakarta.

Ninik Widiyanti. 1987. Kejahatan dalam Masyarakat dan Penegakannya. Penerbit. Bina Aksara. Jakarta.

Rodo Venesia H Pandiangan. (2018). Pertanggungjawaban Pidana Terhadap Premanisme yang melakukan Tindak Pidana Ancaman dan Pemerasan dalam Perspektif Hukum Pidana (Studi Putusan No. 915/PID.B/2014/PN-BDG). Fakultas Hukum. Universitas Sumatera Utara. Medan.

Suyanto. (2018). Pengantar Hukum Pidana. Penerbit. Kencana Prenada Media Group. Jakarta.

Topo Santoso dan Eva Achjani Zulfa. (2003). Kriminologi. Penerbit. PT Raja Grafindo Persada. Jakarta.

Undang-Undang Nomor 1 Tahun 1946 Tentang Kitab Undang-Undang Hukum Pidana (KUHP). 